TAO, Vol.5, No.4, 499-514, December 1994

\title{
Gravity and Magnetic Studies in the Tatun Volcanic Region
}

\author{
CHIEH-HOU YANG ${ }^{1}$, TAI-CHYE SHEI ${ }^{1}$ and CHUNG-CHIA LUE ${ }^{1}$ \\ (Manuscript received 22 November 1993, in final form 25 November 1994)
}

\begin{abstract}
Gravity and magnetic surveys have been carried out in the Tatun volcanic field in order to analyze the subsurface structures, the extension of the Chinshan Fault and the volcanic rock distribution in the surveyed area. Qualitative interpretation of gravity data indicates that the highest gravity zones are located in the Hengshantsun, Chihsingshan, Tatunshan, Matengshan, and Chutzushan regions, whereas the lowest gravity anomaly is in the Yukuangkengt'ou region.

The inverted density/depth models are comparable to the surface geologic characteristics. The density discontinuous zones are related to the Chinshan fault. The magnetic high anomalous areas, such as the Hengshantsun, Tatunshan, Chutzushan, Hsiaokuanyinshan, and Yangmingshan regions are also the gravity high regions except for the Chihsingshan region which, however, does show a low magnetic anomaly. Gravity and magnetic studies reveal comparable results. The geophysical anomalies support most of the major geological features presented in the studied area.
\end{abstract}

(Key words: Tatun, Gravity and Magnetism)

\section{INTRODUCTION}

Regional gravity and magnetic surveys covering about 500 square kilometers have been done in the Tatun volcano group area, northern Taiwan. Major geologic features in the surveyed area and its vicinity are the Chinshan fault, Hsinchung fault and the Kanchiao fault. Rocks occur as andesitic lavas and pyroclastics ranging in age from the late Pliocene to the early or middle Pleistocene (Juang and Bellon, 1984).

The geology and geophysics of the Tatun volcanic groups have been extensively studied (Ogasawara and Ooe, 1932; Torii, 1936; Yen and Chen, 1953; Sun and Hsieh, 1957; Chen and Wu, 1971; Yen et al., 1984; Lee et al.,1985; Wu et al., 1981, 1983; Juang and Bellon, 1984; and Tzou and Yu, 1987 ). Tzou and Yu interpreted the gravity data by using upward continuation and direct modeling methods and obtained some conclusions. However, the lack of data in the central part of the surveyed area (i.e., in the vicinity of the Chutzushan

1 Institute of Applied Geology, National Central University, Chung-Li, Taiwan, R.O.C. 
region) due to the Armed Forces prohabition on such a survey left the results incomplete. In order to make up for this drawback and get a better picture of the subsurface geology, the same gravity and magnetic surveys were carried out in the Tatunshan area especially in the formerly forbidden area from March to October, 1989, under the financial support of the Yangmingshan Administration and also with permission from the Chinese Air Force.

Here the authors present the inversion results of gravity data obtained from the 2257 stations which covered an area of 500.square kilometers. Since magnetic data have been used as an effective means of mapping the geological structure, especially in the reconnaissance stage of exploration, the magnetic data were also collected from 500 stations in an area of 360 square kilometers. The survey had the following major objectives: to delineate the buried volcanic rocks and to define the major structural relief. The results of the study yield a significant increase in the understanding of the geologic structure of the area.

\section{GEOLOGIC SETTING}

The Tatun volcano group area is situated in the northern tip of Taiwan (see index map in Figure 1). In the surveyed area, Tatunshan is $1081 \mathrm{~m}$ in elevation at its peak. This volcano is surrounded by Tsaikungkenshan $(832 \mathrm{~m})$ to the north, Hsikuanyinshan $(1063 \mathrm{~m})$ to the northeast, Mientienshan $(977 \mathrm{~m})$ to the west, Tatunnanshan $(980 \mathrm{~m})$ to the south, and Chihsingshan $(1120 \mathrm{~m})$ to the east. Chutzushan $(1103 \mathrm{~m})$ is located in the north of Chihsingshan. The andesitic lavas and pyroclastics are underlain by the Mio-Pliocene strata which constitute the basement of the volcanic region.

According to Juang and Bellon (1984), the main volcanic activity of the Tatun volcano group shows an age ranging from the late Pliocene to the early or middle Pleistocene, and shows a general eruption series from old to young as follows: the lower lavas of the Chihsingshan subgroup \Chutzushan subgroup \Huangchuishan subgroup\the upper lavas of the Chihsingshan subgroup. The volcano group comprises about 20 volcanoes and volcanic domes covering an area of approximately 350 square kilometers. More than 15 lava flows and extensive pyroclastic accumulations are distributed in the central part of this volcano group which can be divided into subgroups named Tatunshan, Chutzushan, Chihsingshan, Shaokengliao, Neiliaoshan, Huangtsuishan, Nanshihshan, and Tinghuohsiushan. The three tuff-breccia formations are called the lower tuff-breccia, the Tatunshan tuff-breccia, and upper tuff-breccia. The lavas are composed of various types of andesites, such as hornblende , pyroxene-homblende, homblende-pyroxene and pyroxene andesites (Yen and Chen, 1953). The geologic map of the study area and its vincinity is shown in Figure 1.

Fumaroles, hot springs and hydrothermal alteration zones are aligned in a narrow belt that extending from Hsinpeitou to Chinshan and which becomes geothermally active in this volcanic region.

\section{GEOPHYSICAL SURVEYS}

\subsection{Gravity Survey}

National Central University (NCU) conducted a gravity reconnaissance survey over the Tatun area during the years 1979-1982 (Tzou and Yu, 1987). About 3000 stations (2221 observing data were adopted in this study) were established covering an area of 500 square 


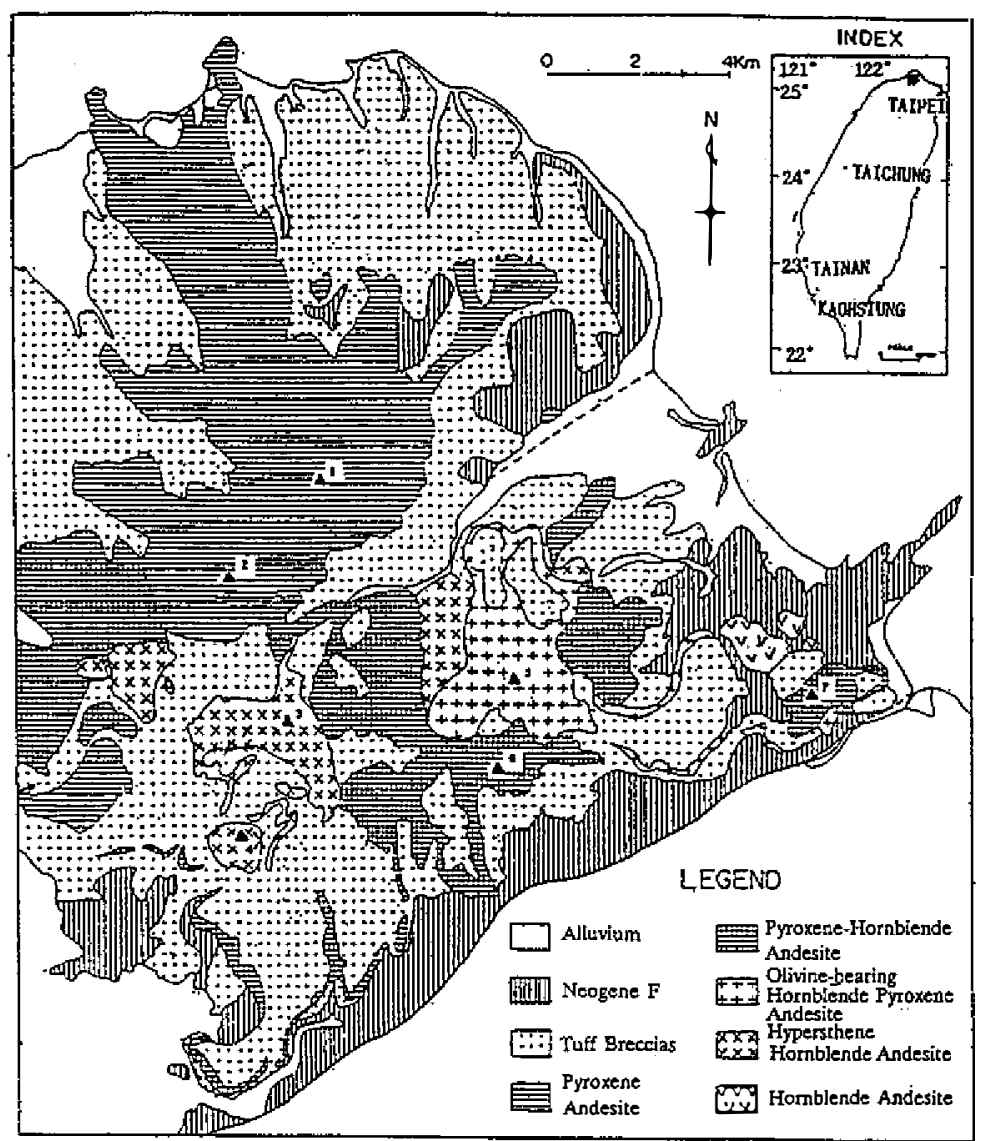

Fig. 1. Geologic map of the study area and its vincinity. Numbers refer to the locations: 1. Chutzeshan; 2. Hsiaokuanyinshan; 3. Chihsingshan; 4. Shamaoshan; 5. Huangtsushan; 6. Tachienshan; and 7. Tinghoshiushan. (from Juang and Bellon, 1984).

kilometers. Unfortunately, the original surveyed area did not cover the most important part of Chutzushan region due to the regulations forbiddance imposed by military administration. Recently however, extended gravity and magnetic surveys were carried out in this area with the permission of the General Headquarters of the Air Force. Thirty-six stations were established, and these were calibrated to the old values of gravity at bench marks labeled 1203 at Fengyutsun, Chinshan county, both the absolute value of this point at 978, 982.92 mgals. Worden gravity meters with scale constants of about 0.01 milligals were used throughout the survey. Figure 2 presents the gravity survey index map which shows the distribution of the 2257 stations. The numerical symbols shown in the edges of the map are 2" TM aerial photographic coordinates.

Gravity stations were chosen at points that were readily recognizable on the topographic maps and were usually spaced $150 \mathrm{~m}$ to $300 \mathrm{~m}$ apart at convenient points along the main access roads. Elevation control of the stations was obtained by using an AGA geodimeter instead of the NIKON NT-3A by Tzou and Yu (1987). Gravity bases were reoccuppied about 2 hours, when possible, and frequent repeats of gravity readings were made at intervening gravity stations for close drift control. 


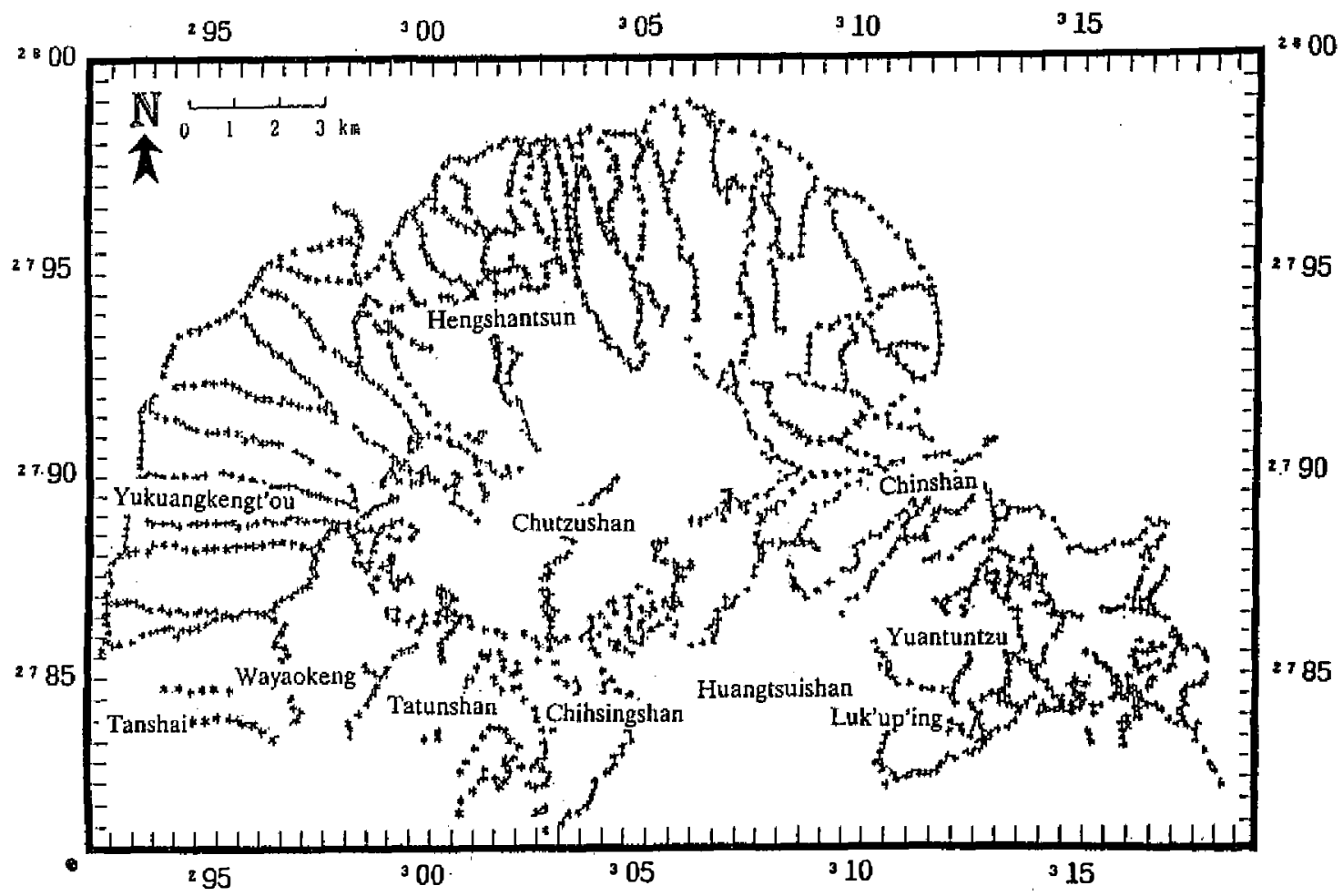

Fig. 2. Locations of gravity measurement. Numerical symbols are 2" TM aerial photographic coordinates.

\subsection{Magnetic Survey}

A magnetic survey at the Tanshui region was done between August 1987 and July 1988, and the one in the region between Tatunshan and the west of Huangtsuishan was done one year later (August 1988 to July 1989) with a Scintrex MP2 proton magnetometer in addition to a MFD-4 flux-gate magnetometer. About 500 magnetic stations covering an area of about 360 square kilometers (Figure 3) were established. Aerial photogrammetric maps at a 1:5000 scale were used to controlling station positions.

\section{DATA REDUCTION}

\subsection{Gravity}

Standard methods were employed to analyze the gravity data. Theoretical values of the studied points were first determined by using the "International Formula" of spheroidal gravity of 1930. Then, an elevation factor of 0.2076 milligals per meter was used to make the terrain correction. This factor, which corresponds to a density of 2.41 grams per cubic centimeter for this area, was determined by Tzou and Yu (1987). It was generally applied to the distance between 0-20 m; however, Hammer's tables (1939) was applied to the distance in the range of $20-890 \mathrm{~m}$ based on the aerial photogrammetric map with a scale of 1:5000, and for a distance beyond $890 \mathrm{~m}$, the terrain correction was derived from multiquadric equations by using Lin's algorithm (1979). 


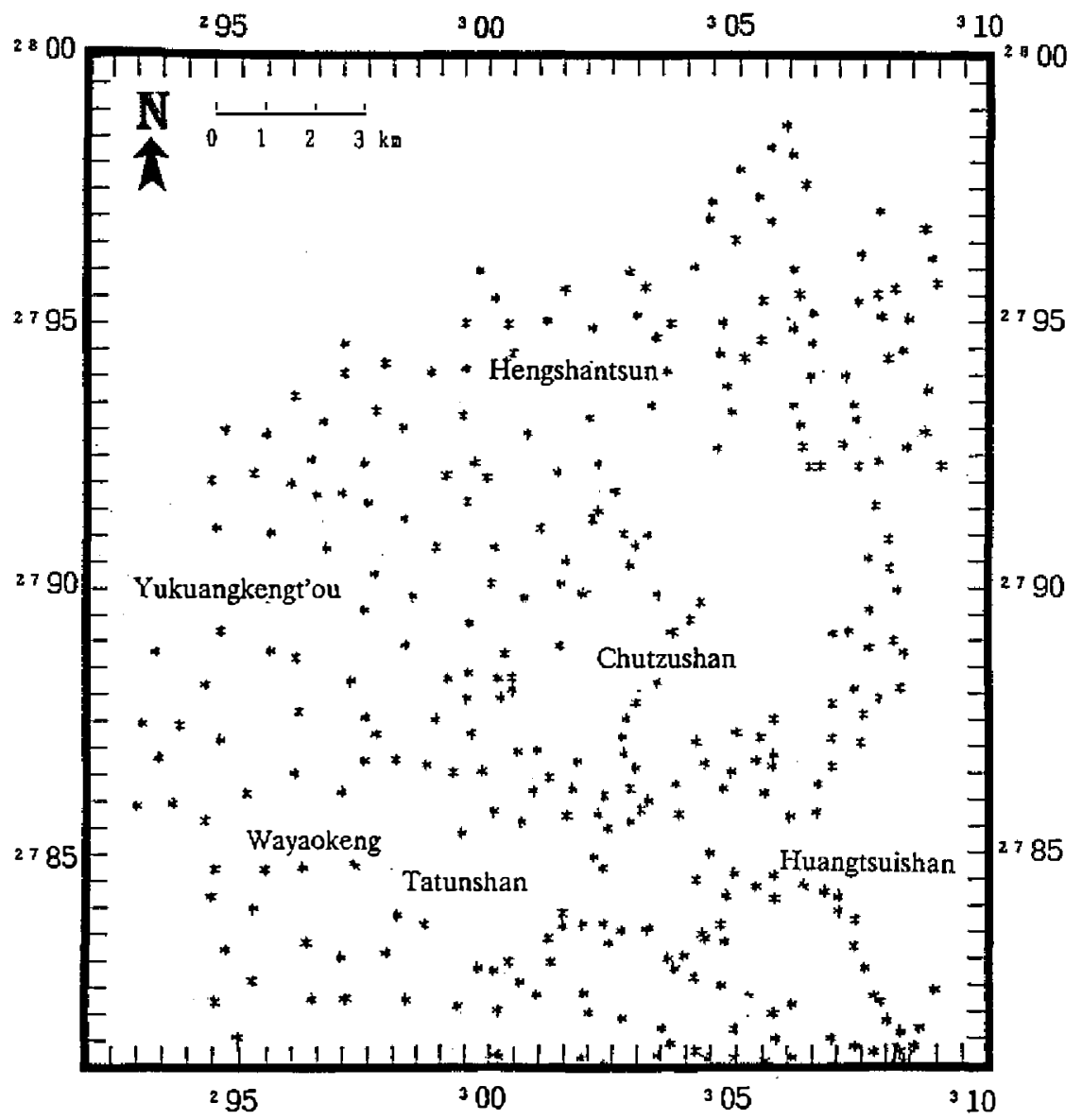

Fig. 3. Locations of magnetic measurement.

Figure 4 shows the contour of the Bouguer gravity anomaly map corrected for the given reference spheroid and the reduction density. The contour interval on the map is 4 mgal.

\subsection{Magnetism}

The magnetic data were studied by standard procedures described by Telford et al. (1977). Corrections for instrument and the daily variation within 2-hour repeated readings are made at magnetic bases and intervening stations. Removing the earth's main field for each station is done by referring to the Gauss coefficients shown in the International Geomagnetic Reference Field table (IGRF) (IAGA, 1986).

\section{DATA PROCESSING AND INTERPRETATION}

\subsection{Gravity Qualitative Interpretation}

In the Bouguer gravity map (Figure 4), the most prominent gravity anomalies in the area are gravity highs (e.g., Hengshantsun, Chihsingshan, Tatunshan, Matengshan, and Chutzushan regions etc.) associated with the volcanic piles of the Tatun volcano group, which are slightly denser than the surrounding sedimentary rocks. 


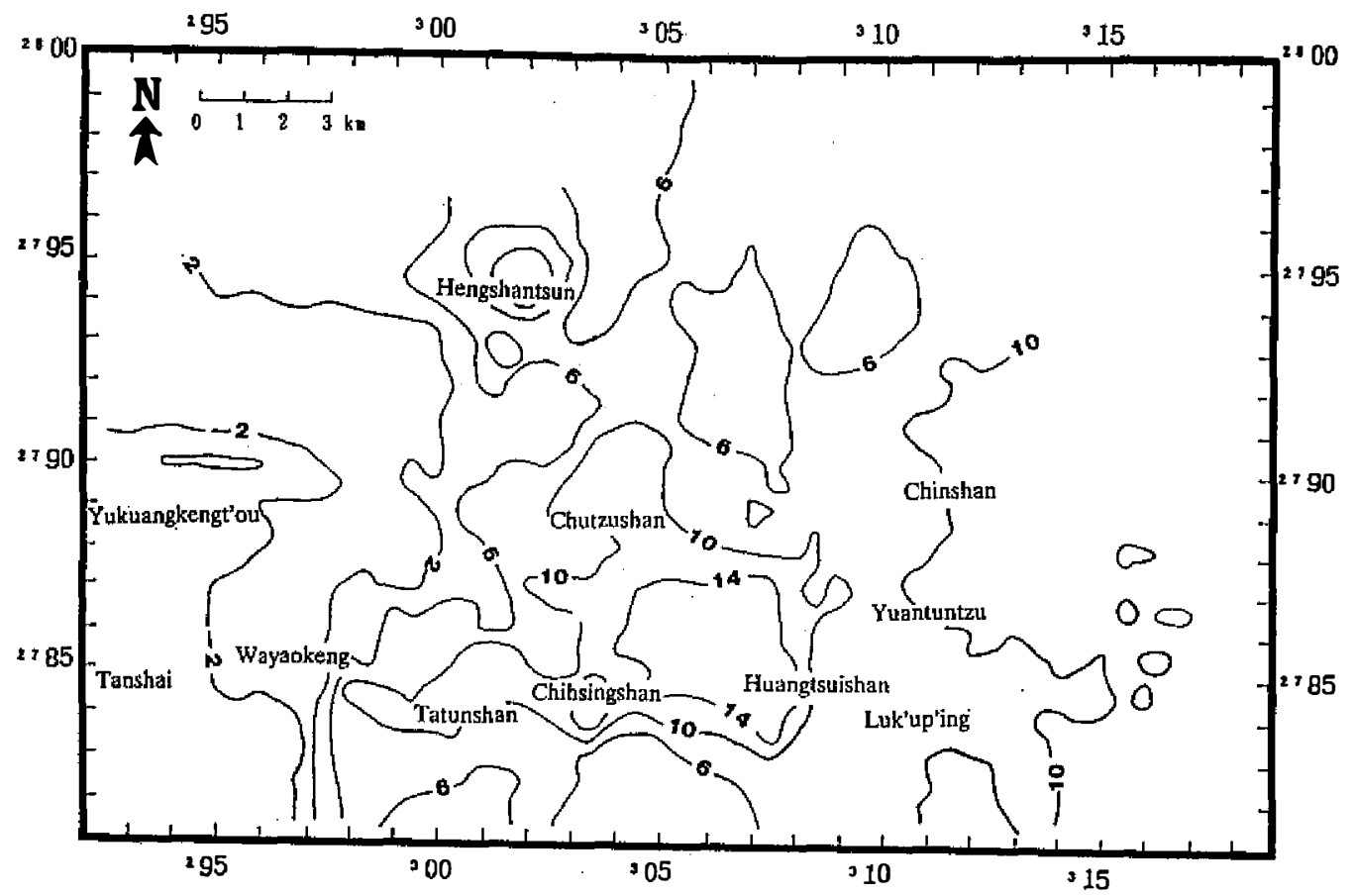

Fig. 4. Bouguer gravity anomalies. Contour interval is $4 \mathrm{mgal}$.

Broad positive and negative regional anomalies are obtained by using second-order polynomial least-square fitting techniques (Coons et al., 1967). Such anomalies are related to structural and lithologic changes in the basement rocks and also to the thickness of the overlying volcanic rocks. This regional gravity anomaly (Figure 5) probably extends into the Tatun volcano group area and gives rise to a westward decrease in anomaly values across the surveyed area. The gradient, however, does not appear to be significant, at least in comparison with the amplitudes of the local anomalies in the northeast of Chinshan.

Residual gravity and second derivative methods (Rosenbach, 1953) have been used to isolate anomalies because they tend to magnify local events. The major gravity anomalies can be related to the geological features (Figure 6 and Figure 7). The gravity high centered on Hengshantsun and Yangmingshan outcrop by andesitic lavas. The associated geological features are designated to the large andesitic pipes. The gravity high at Chihsingshan, Tatunshan, Matengshan and Chutzushan regions may be related to the volcanic necks. On the other hand, the gravity low located at Yukuangkengt'ou region is designated to associate with the sedimentary rocks. Deeper structures can be sensed by adopting a larger radius (Figure 7). The high gravity anomalies at Hengshantsun, Chihsingshan, Tatunshan, Matengshan and Chutzushan are still recognized in spite of the introduction of false anomalies with this method. The gravity profiles along AA', BB' and CC', shown in Figure 8, have been constructed based on the residual gravity map (Figure 6).

Severe disturbances among the residual gravity profiles shown in Figures 9, 10 and 11 might suggest the existence of faults. The gravity anomaly at Yuantuntzu is negligible at a greater depth (Figure 7(a), (b), (c)), but the possible presence of high density rocks at shallow depths may have caused this anomaly. On the other hand, the anomaly in the Yukuangkengt'ou region decreases with increasing depths (Figure 7(a), (b), (c)) confirming a possible buried channel with a depth less than $300 \mathrm{~m}$ as suggested by Tzou and Yu (1987). 


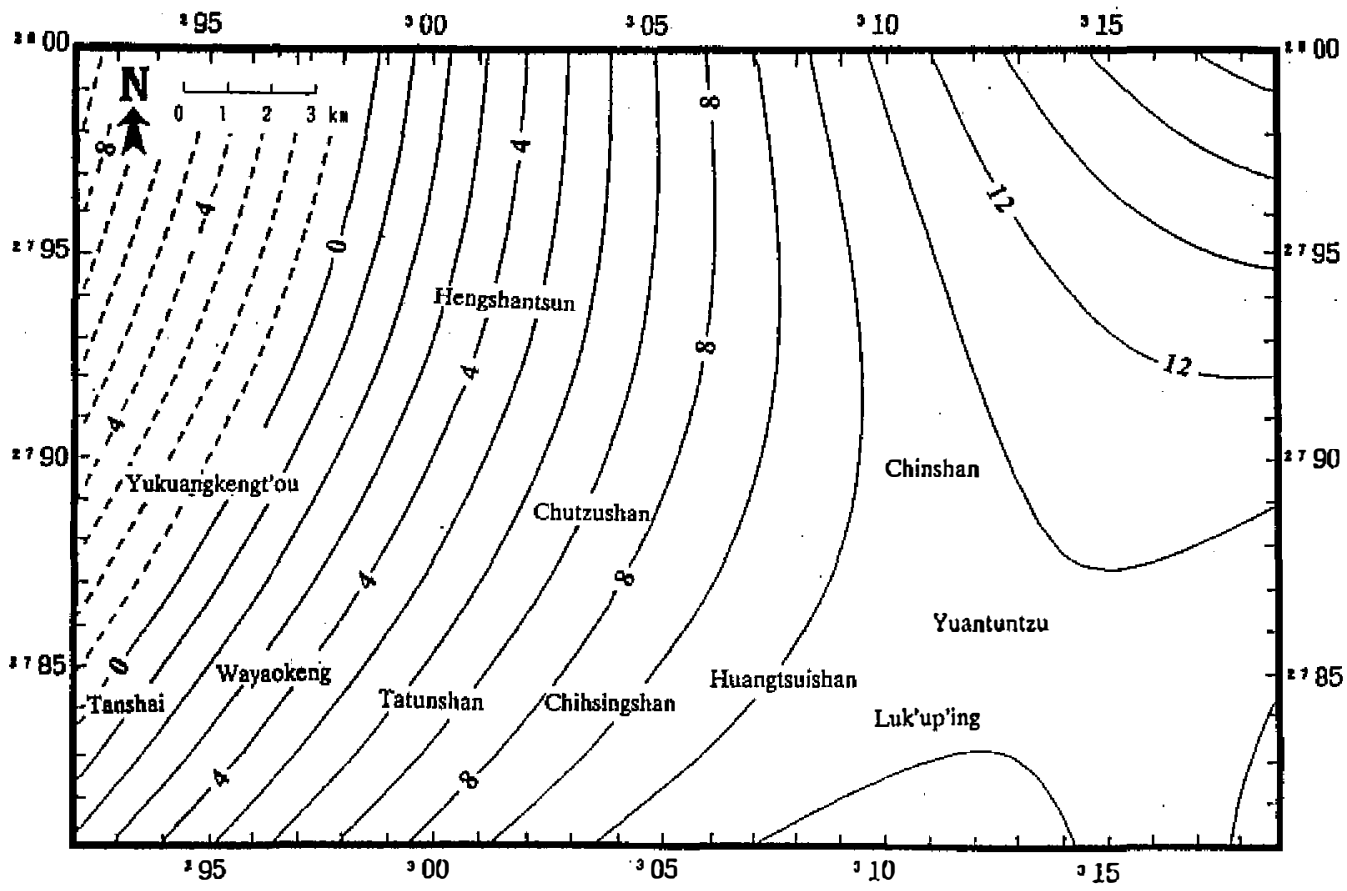

Fig. 5. Regional gravity map. Contour interval is $1 \mathrm{mgal}$.

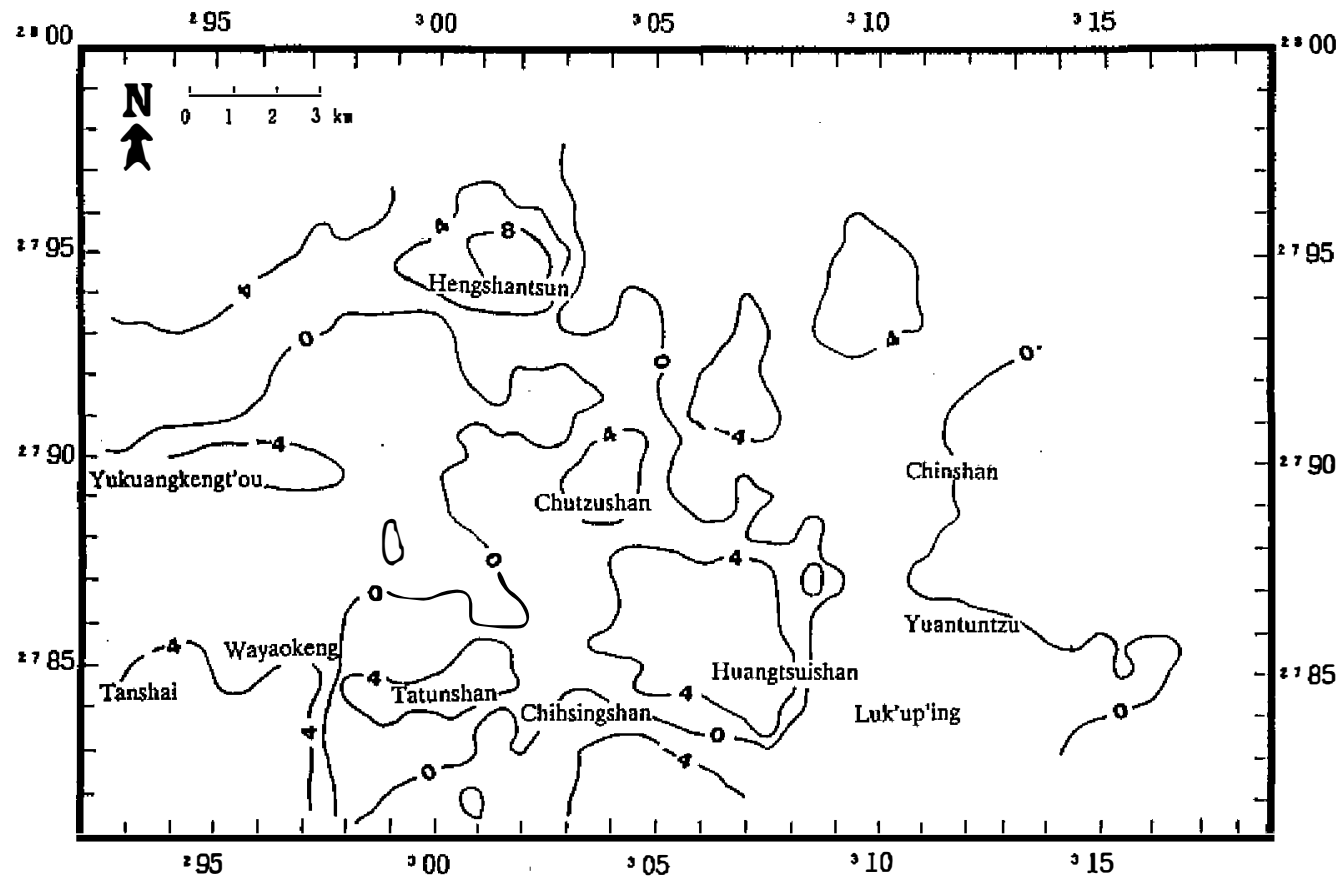

Fig. 6. Residual gravity anomalies. Contour interval is $4 \mathrm{mgal}$. 


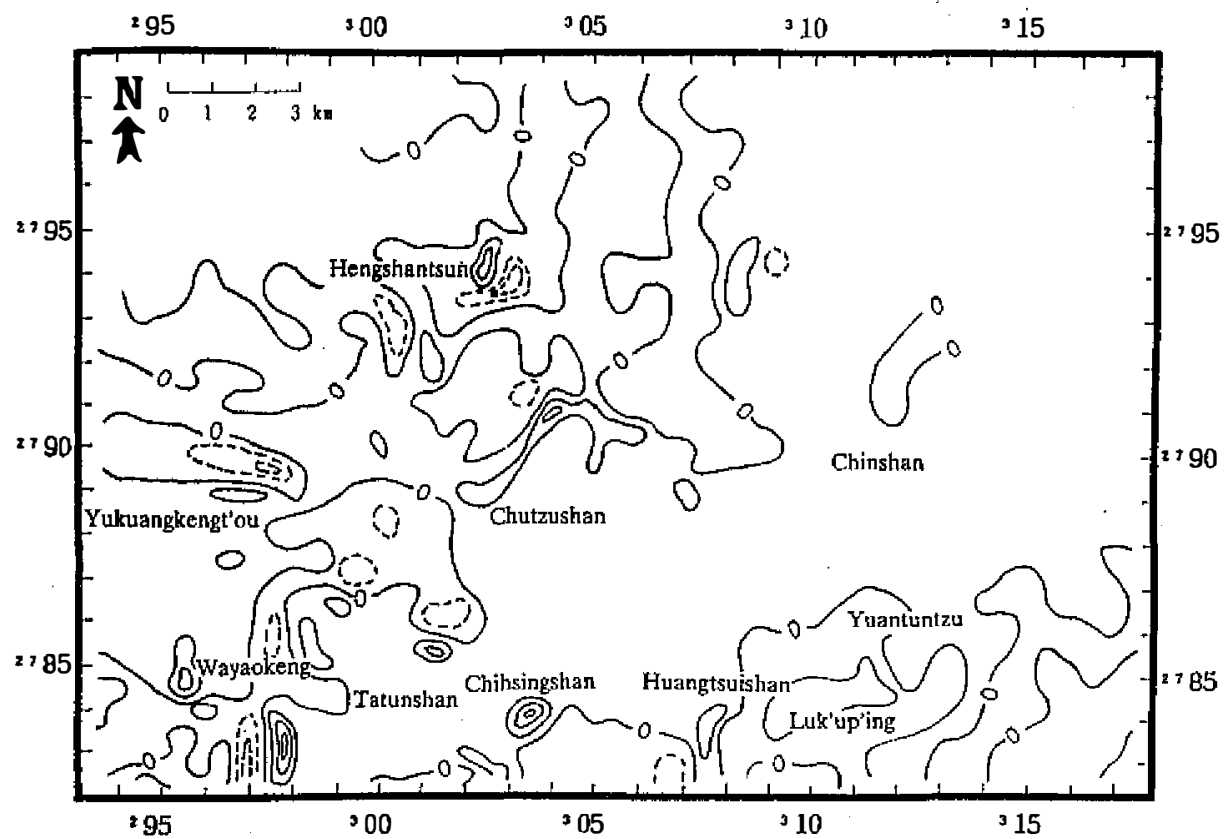

(a)

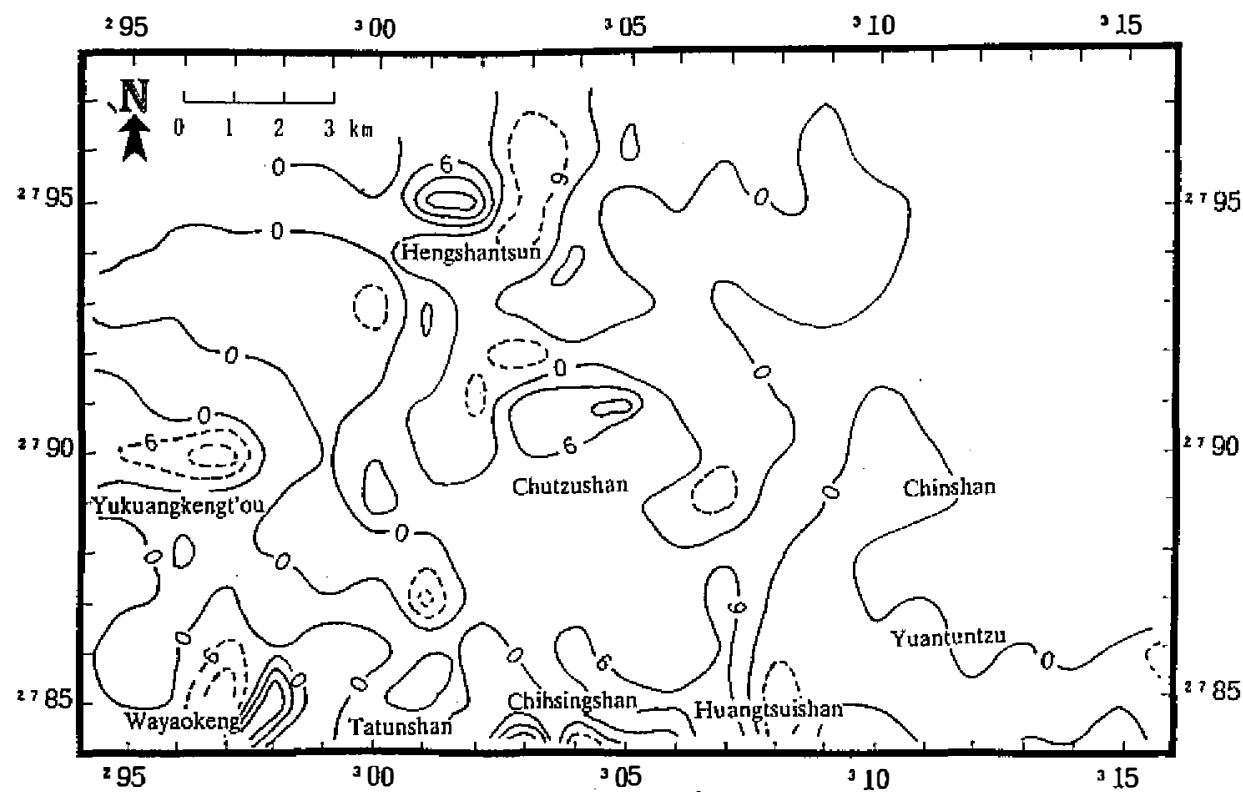

(b)

Fig. 7. Second-derivative gravity maps for different calculating radii $\mathrm{R}:$ (a) $\mathrm{R}=\sqrt{5 / 2}$, (b) $R=\sqrt{5}$, and (c) $R=3 \sqrt{5 / 2}$. The contour interval shown in Figs.(a) and (c) is $4 \mathrm{mgal}$; the contour interval shown in Fig.(b) is 6 mgal. 


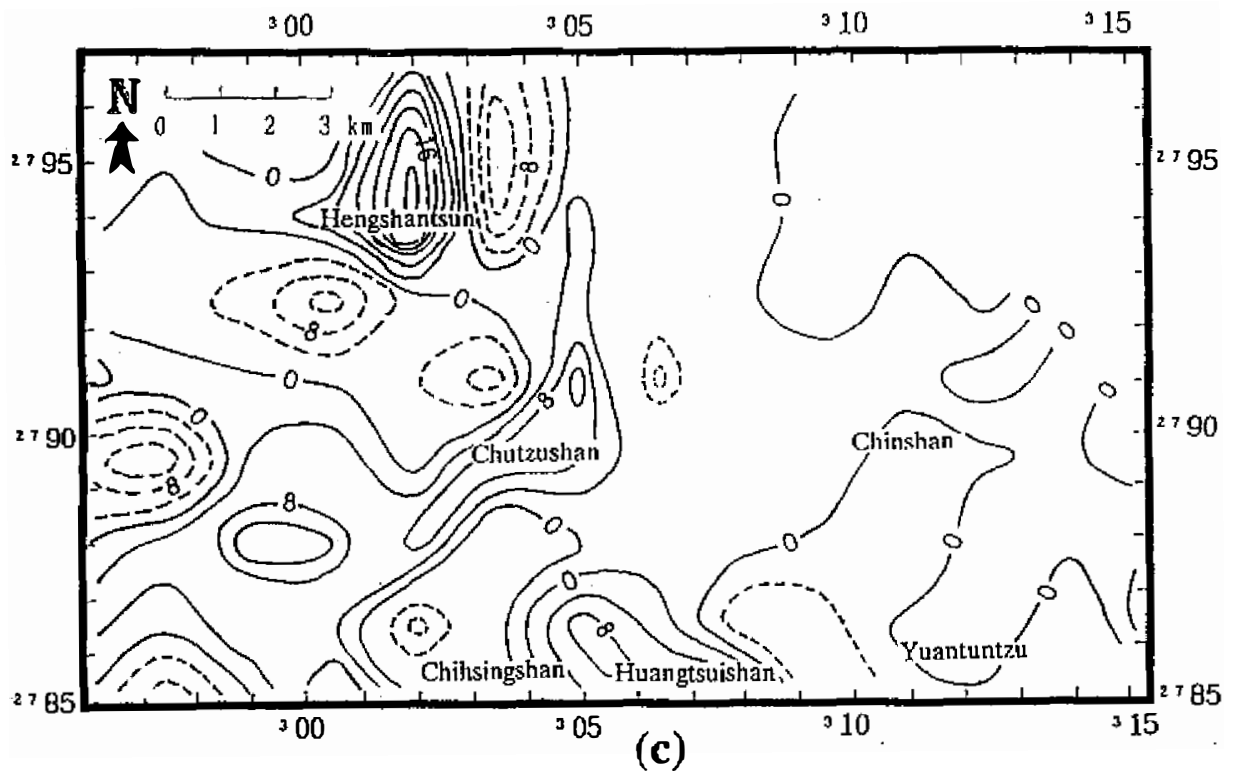

Fig. 7. (Continued)

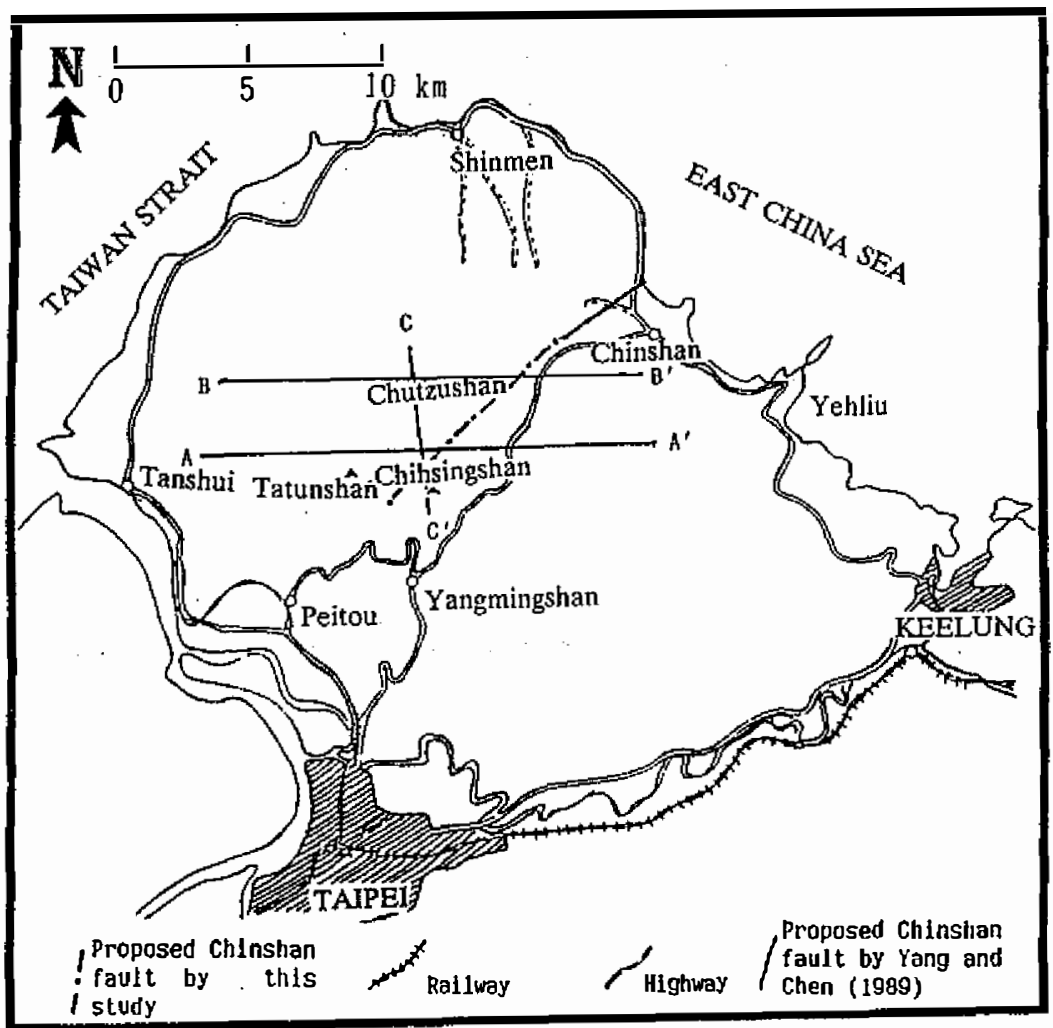

Fig. 8. Location of gravity profiles $\mathrm{AA}^{\prime}, \mathrm{BB}^{\prime}$ and $\mathrm{CC}^{\prime}$ and the possible extension of the Chinshan fault. 


\section{2 Gravity Inversion}

In order to decrease the influence of regional anomalies in obtaining a reasonable subsurface structure, the residual gravity profiles AA', BB'and CC' (Figures 9, 10,11) are used to generate the density/depth model for each section, and the well known stochastic inversion technique (Franklin, 1970) is employed to calculate rock densities and set bounds between two rock units of different densities.

Basically, this method handles two-dimensional (2-D) problems with a single continuous interface along which density contrasts are found. The models are comprised of rectangular prisms extending infinitely in the direction perpendicular to the gravity cross-section. The initial models have dimensions of $80 \mathrm{~km} \times 8 \mathrm{~km}$. The constraints of dimension and density contrast for each rectangular prism are derived from the features of the residual gravity and geology. During iterations, the depths are fixed, while the densities are allowed to vary in order to obtain a better fit at the measuring positions between the measured and model data. The applied computer program written by Yeh and Yeh (1982) is based on a stochastic approach (Franklin, 1970).

The results of the inversion are smoothed out by grouping the rectangular prisms which are considered the same rock units. They are presented in Figures 9,10 and 11. This relates to the previous small magma channel now filled by the volcanics. The large volume of higher densities shown in Figures 9-11 can perhaps be interpreted as thick andesitic rocks in the area, and these zones are near the Chutzshan (position P), Chihsingshan (position Q) and Tatunshan regions. The density discontinuity shown in these figures might indicate the presence of a fault. This fault passes through the Chutzushan and Chihsingshan areas along the northeast direction and then passes the area between Chihsingshan and Tatunshan. This is a thrust fault with a dip between 66 and 79 degrees. It could be the extension of the Chinshan fault (Figure 8) (Yang and Chen, 1989).
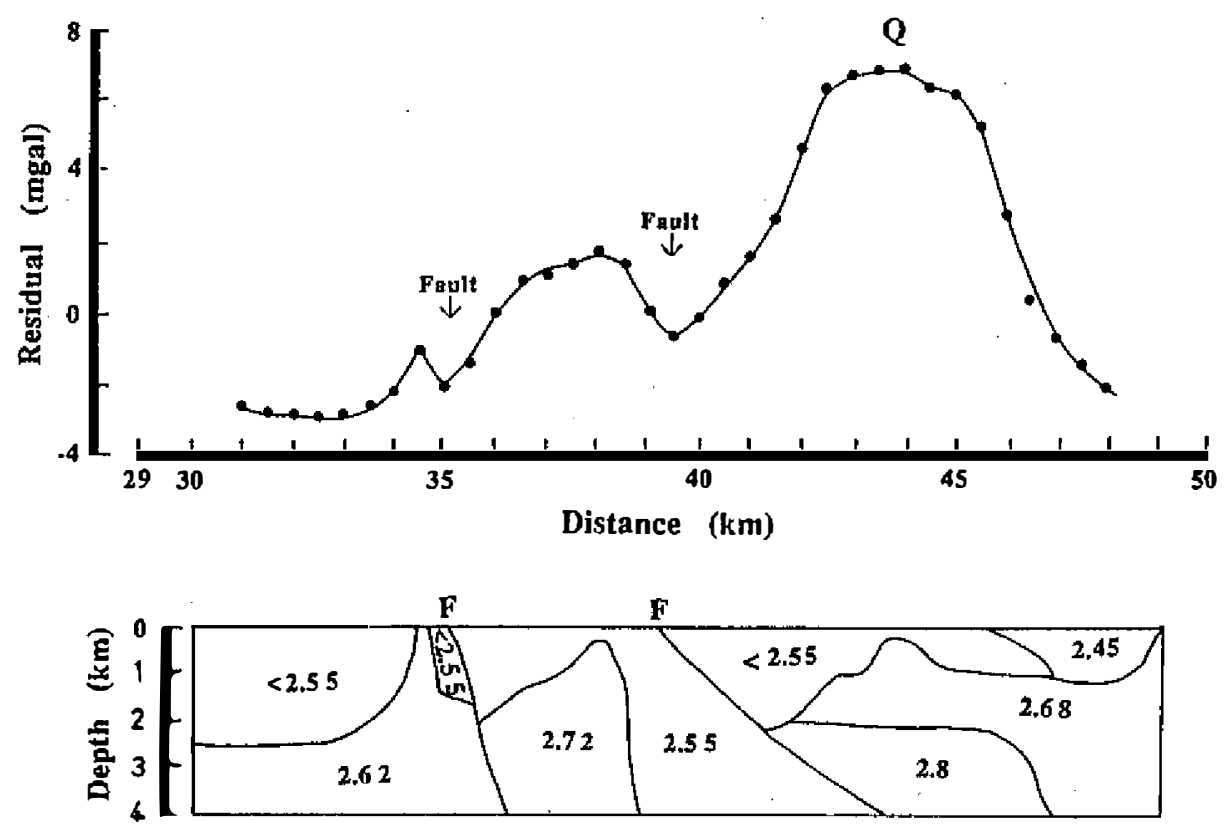

Fig. 9. Residual gravity profile $\mathrm{AA}^{\prime}$ and its interpretation. Symbol Q indicates the location of Chihsingshan. 

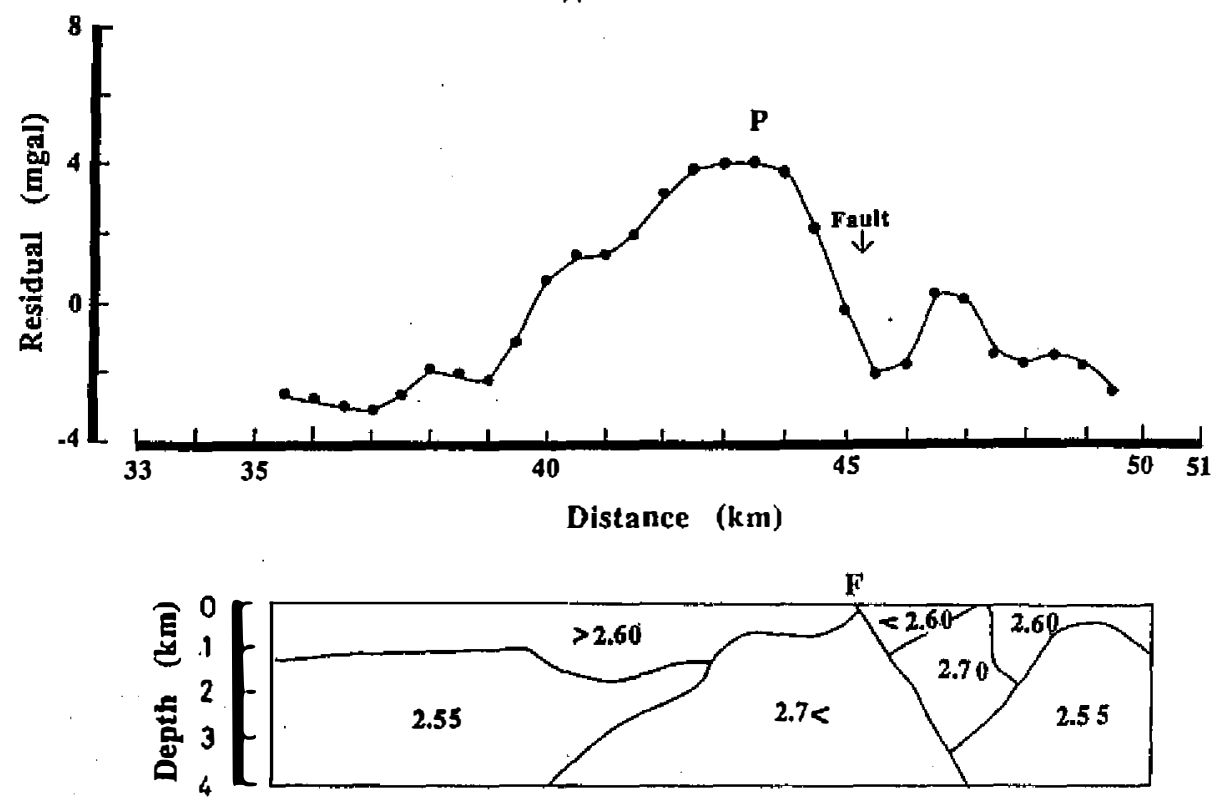

Fig. 10. Residual gravity profile BB' and its interpretation. Symbol P indicates the location of Chutzushan.
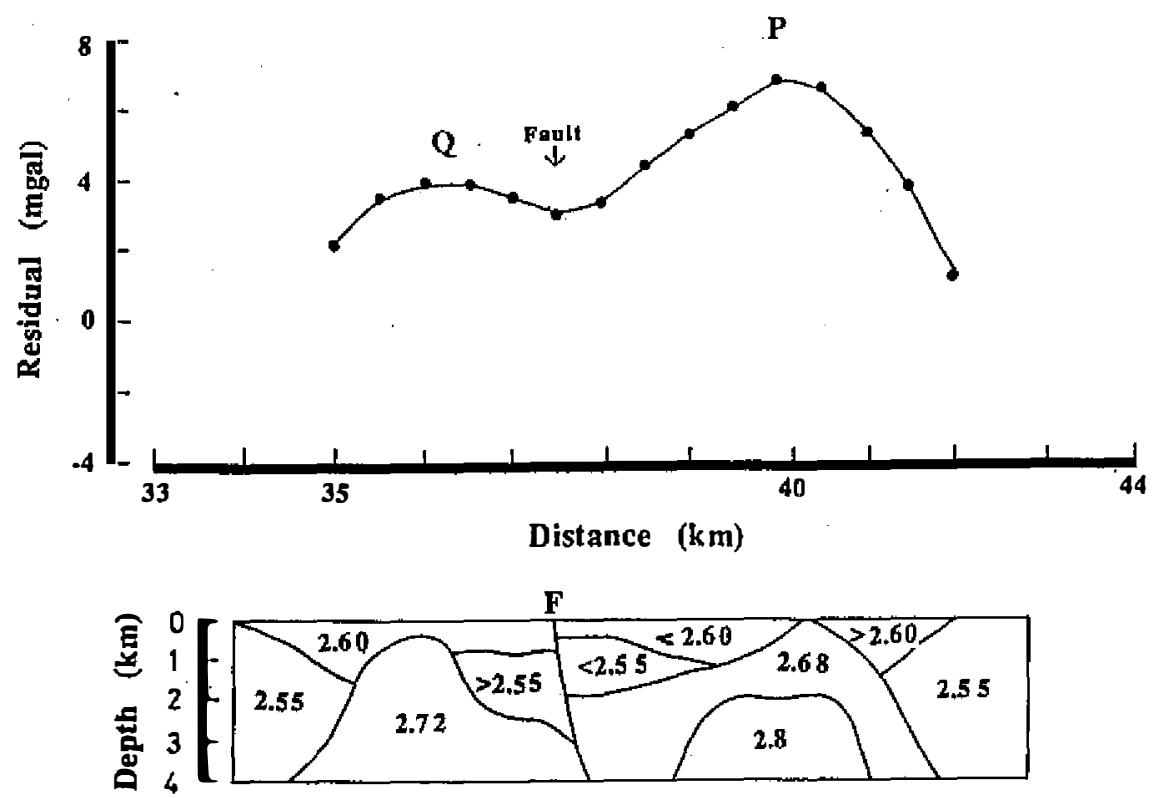

Fig. 11. Residual gravity profile $\mathrm{CC}^{\prime}$ and its interpretation. Symbols $\mathrm{P}$ and $\mathrm{Q}$ indicate the locations of Chutzushan and Chihsingshan respectively.

\section{3 Magnetic Interpretation}

The regional magnetic intensity anomaly for the total and vertical components can be fitted using the least square method with a five-order polynomial. The regional magnetic anomaly maps shown in Figures 12 and 13 indicate that the higher anomalies appear in the 


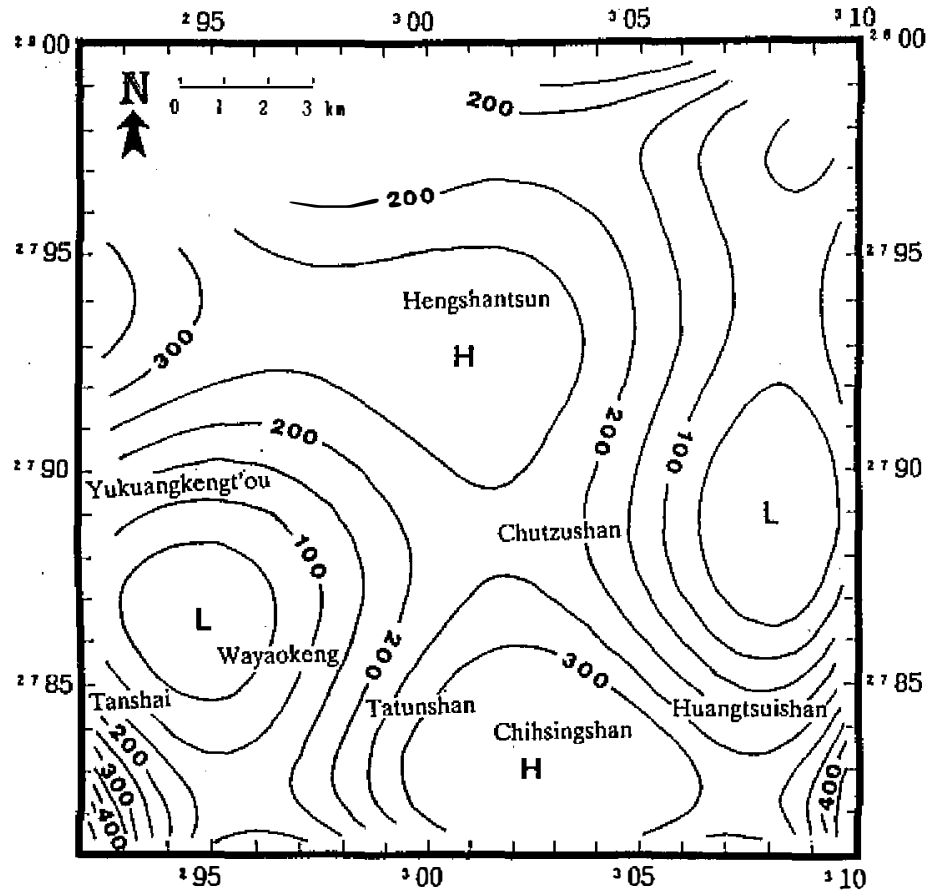

Fig. 12. Regional total intensity magnetic anomaly map. Contour.interval is 50 gamma.

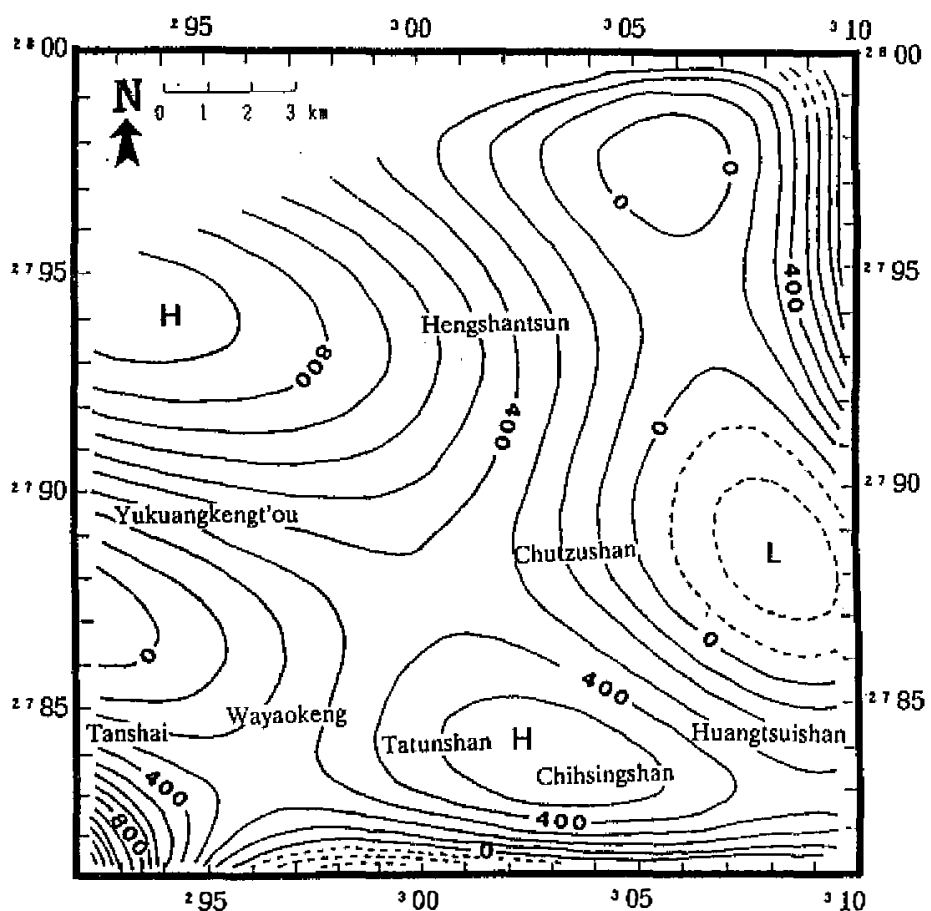

Fig. 13. Regional vertical intensity magnetic anomaly map. Contour interval is 100 gamma. 
southwestern part of the surveyed area while the lower anomalies are located in the vicinity of Tanshui, Chutzushan and Sungshan. The decrease in regional magnetic values from the southeast (i.e. Tatunshan and Chisingshan) to the northwest (e.g. Tanshui) is designated as the magnetic basement which dips gently toward the northwest. The regional gravity trends reflect the same structural patterns as the magnetic results do. Figures 14 and 15 show the residues of total and vertical magnetic intensity. The higher magnetic anomalies found at Tatunshan, Chutzushan and Hsikuanyinshan suggest the presence of intrusive rocks or a large volume of andesite underneath. A comparsion made between the gravity results and the magnetic results reveals both are quite similar; high magnetic anomalous zones such as the Tatunshan, Chutzushan, Hsikuanyinshan, Yangmingshan and Hengshantsun areas are also the high gravity zones except for the Chihsingshan area which has a low magnetic anomaly rather than a high one. This exception indicates that the andesitic rocks in this area contain less/fewer ferromagnesian minerals. The andesitic rocks in that area have been extensively hydrothermaly altered, and the ferromagnesian minerals in the rocks may have partially or completely been weathered out. Since the magnetic intensity in this area is comparable to that in other low intensity areas, it may be assumed that the ferromagnesian minerals were completely leached out or transformed to other non-magnetic minerals.

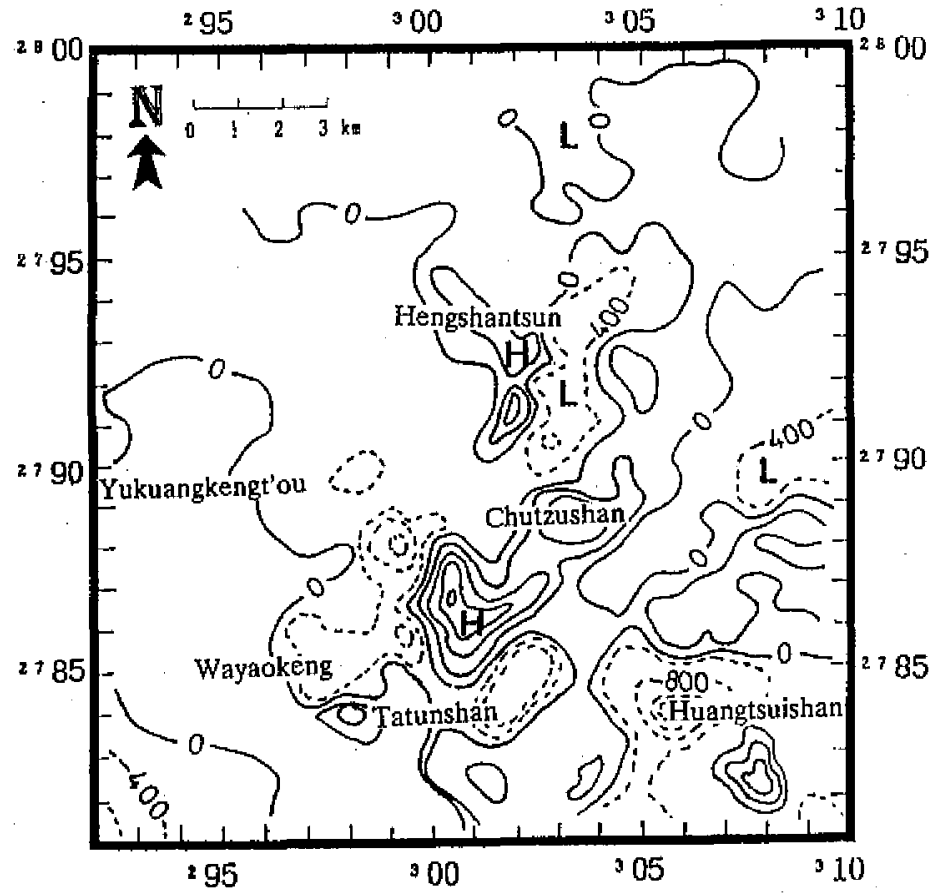

Fig. 14. Residual of total intensity magnetic map. Contour interval is 400 gamma.

\section{CONCLUSIONS}

This paper models gravity and magnetic anomalies and provides the outcrop geology with a tectonic framework in the Tatun volcanic region. Attention is also drawn to gravity and magnetic anomalies which are probably not indicative of surface rock type. 


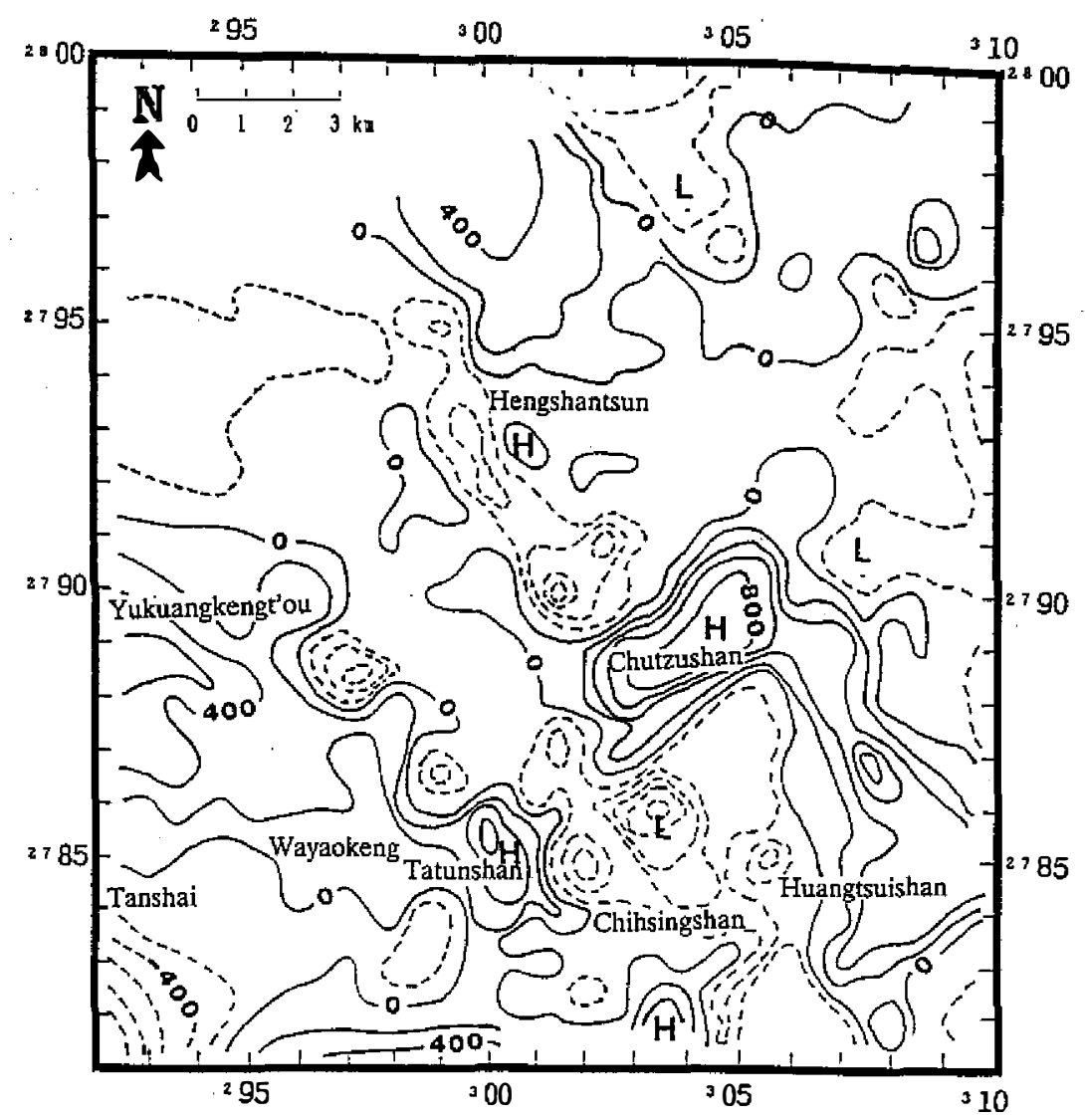

Fig. 15.Residual of vertical intensity magnetic map. Contour interval is 200 gamma.

The major conclusions drawn from the present studies are as follows:

(1) The basement beneath the surveyed area dips gently to the northwest.

(2) Thick andesitic rocks may be present in the Tatunshan, Chinsingshan, Huangtsuishan, and Chutzushan regions. An intrusive rock or a buried old volcanic rock may exist near Hengshantsun. The volcano of Chutzushan may extrude upward through the Wuchihshan Formation and plunge to the east. Similarly, the volcano at Chihsingshan may extrude upward and plunge toward to the northwest.

(3) It is possible that a northeastern high angle thrust fault passes westward through the region between Chutzushan and Chihsingshan. It may also go through the region between Tatunshan and Chihsingshan.

(4) The Yukuangkengt'ou and Tansui regions may have a buried ancient channel.

(5) A local high magnetic zone in the Yangmingshan region may be related to the surface lava. However, the Chihsingshan region has a local high gravity zone but a low magnetic anomaly. It is designated to the presence of high density but low magnetic rock within the subsurface. This also could be the result of hydrothermal alternation, i.e. the magnetic minerals in the rocks in the Chinsingshan region may have been removed or transformed to other non-magnetic minerals by thermal activity. 
Acknowledgments The authors are indebted to the Yangmingshan Administration, Republic of China, for their financial support of this study. They would also like to thank Mr. Tzou, Y. H. for providing the gravity data collected from 1979-1882. Gratitude is also extended to Mr. Chen, C. C. for his assistance in collecting and computing the field data.

\section{REFERENCES}

Chen, C. H., and Y. J. Wu, 1971: Volcanic geology of the Tatun geothermal area, northern Taiwan. Proc. Geol. Soc. China, 14, 5-20.

Coons, R. L., P. W. George, and H. Garland, 1967: Structural significance and analysis of mid-continent gravity high. Bull. Am. Assoc. Petrol. Geol., 51, 2381-2399.

Hammer, S. I., 1939: Terrain corrections for gravimeter stations. Geophysics, 4, 184-194.

Huang, C. S., 1988: Geologic map of Taiwan. Central Geological Survey, Sheet 4.

Franklin, J. N., 1970: Well-posed stochastic extensions of ill-posed linear problem. J. Math. Anal. Appl., 31, 682-716.

IAGA ,1986: International geomagnetic reference field revision 1985. EOS, 67, 523.

Juang, W. S., and H. Bellon, 1984: The potassium-Argon dating of andesits from Taiwan. Proc. Geol. Soc. China, 27, 86-100.

Lee, T. Q., P. F. Tsai, and Y. B. Tsai, 1985: Paleomagnetic study of the Tatun volcano group. Bull. Inst. Earth. Sci., Academia Sinica, ROC, 5, 137-150.

Lin, M. 1.,1979: A modified method of gravity terrain corrections using multiquadric equations. Bull. Geophys. NCU, 19, 32-42.

Ogasawara, M., and J. Ooe, 1932: Geologic map of Taiwan: Daitonzan Sheet. Bur. Prod., Government-General of Taiwan.

Rosenbach, O., 1953: A contribution to the computation of the second derivative from gravity data. Geophysics, 18, 894-909.

Sun, C. C., and C. C. Hsieh, 1957: Report on the Chienshanhu structure, Taipei-hsien. (CPC file).

Torii, K., 1938: Topographic-geologic map of the Senzanko oil field. Bur. Prod. GeovernmentGeneral of Taiwan.

Telford, W. H., L. P. Geldart, and D. A. Keys, 1977: Applied geophysics, Cambridge Univ. Press, Cambridge, 860p.

Tzou, Y. H., and G. K. Yu, 1987: Subsurface structure of the Tatun Volcano Group area inferred from the gravity data, Bull. Geophys., NCU, 27-28, 45-60.

Wu, Y. H., T. P. Yen, and Y. H. Tzou, 1982: Geophysical-geologic study on the Tatun volcano group, Yangmingshan area. Report to the National Science Council, ROC, 22pp.

Wu, Y. H., T. P. Yen, and Y. H. Tzou, 1981: Geophysical-geologic study on the Tatun volcano group, the Tansui area. Report to the National Science Council, ROC, 11pp.

Yang, C. H., and C. S. Chen, 1989: Application of the TEM method in the Chinshan fault area. Chinshan, Taiwan. Proc. Geol. Soc. China, 32, 369-381. 
Yeh, Y. H., and Y. T. Yeh, 1982: Inverse of gravity data for subsurface structures by stochasic approach. Bull. Inst. Earth Sci., Academia Sinica, ROC, 2, 61-74.

Yen, T. P., 1958: Cenozoic volcanic activity in Taiwan. Taiwan Mining Industry, 10, 1-39.

Yen, T. P., Y. H. Tzou, and W. H. Lin, 1984: Subsurface geology of the region of the Tatun volcano group. Petrol. Geol. Taiwan, 20, 143-154.

Yen, T. P., and P. Y. Chen, 1953: Geologic map of Taiwan, Nos. 5 and 9 ( scale 1:50,000). Geological Survey of Taiwan. 